\title{
Supporting Information: Relating nanoparticle shape and adhesiveness to performance as flotation collectors
}

\author{
Xiaofei Dong, Heera S. Marway, Emily D. Cranston, Robert H. Pelton* \\ Department of Chemical Engineering, McMaster University, 1280 Main Street West, Hamilton, \\ Ontario, Canada L8S 4L8 \\ *Corresponding author: peltonrh@mcmaster.ca
}

\section{Nanoparticle Characterization:}

Infrared spectroscopy spectra of dried nanoparticles were collected with a Nexus 6700 Fouriertransform infrared (FTIR) spectrometer (Thermo Fisher Scientific Inc.). The nanoparticle tablets were prepared by mixing dried nanoparticles with $\mathrm{KBr}$ and pressing at 10,000 psi with a hydraulic press (Carver, Inc. USA) for $5 \mathrm{~min}$ at room temperature in a stainless steel mold.

X-ray photoelectron spectroscopy (XPS) measurements were performed on dried nanoparticles using a PHI Quantera II XPS scanning microprobe (Physical Electronics (Phi), Chanhassen, MN) equipped with a $1486.7 \mathrm{eV}$ monochromatic Al-K-alpha X-ray source. All settings were controlled through supplied software (Multipak 9.4.0.7) and spectra were collected using a beam size of $200 \mu \mathrm{m}$ and a pass energy of $280 \mathrm{eV}$.
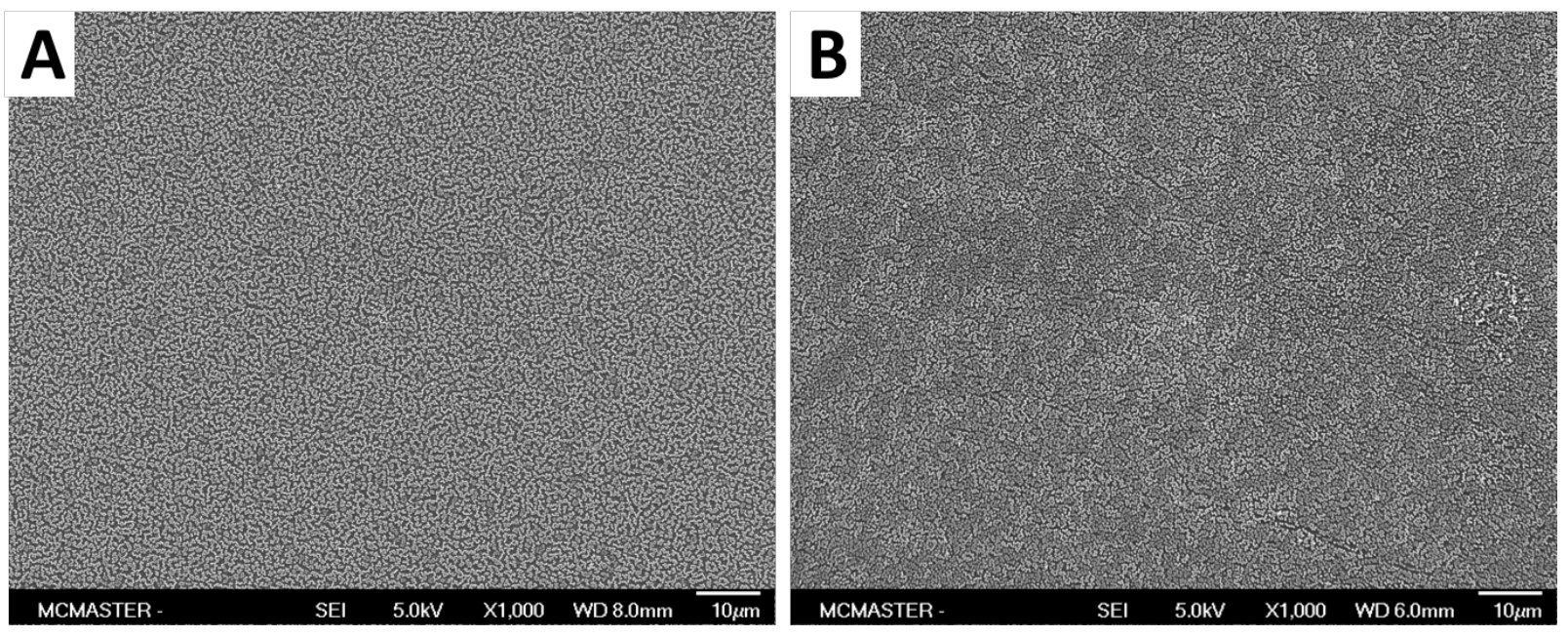

Figure S1. Image A is the SEM image of polystyrene nanoparticles (PS317) treated glass slide whereas image B shows the core-shell nanoparticles (PS-PB3) treated glass slide for contact angle measurements. 


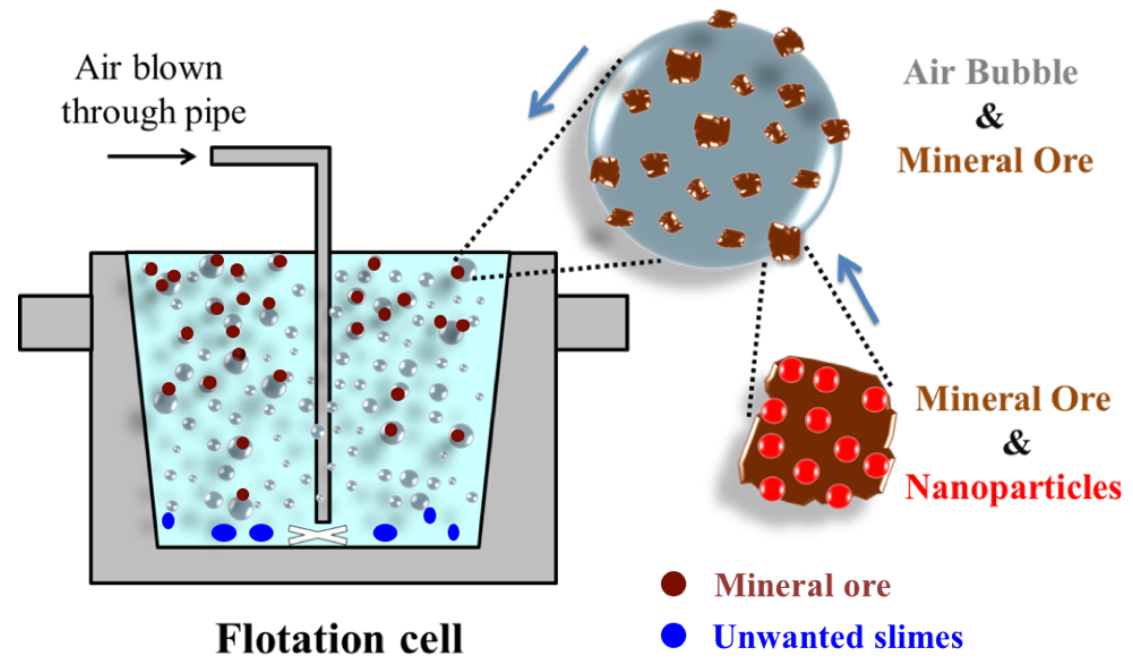

Figure S2. Illustration of the froth flotation process. 


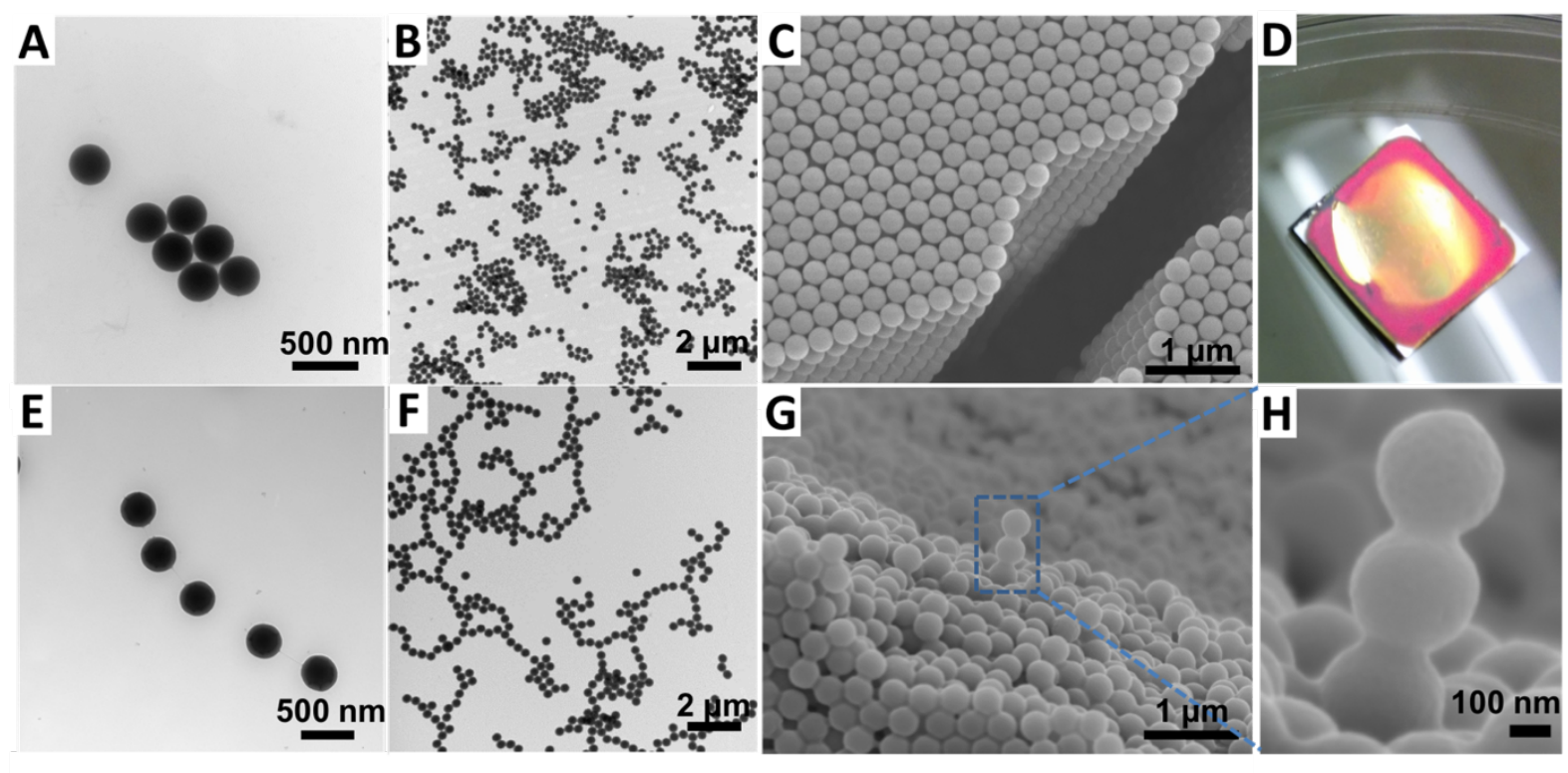

Figure S3. (A and B), TEM images of PS317 seed nanoparticles; (C), SEM image of polystyrene seed nanoparticles; (D), photograph of dried, opalescent polystyrene seed latex on a silicon wafer; (E and F), TEM images of synthesized PS-PB3 nanoparticles; (G) and (H), SEM images of PS-PB3 nanoparticles. 


\section{FTIR of Polystyrene-core-poly(n-butyl methacrylate)-shell Nanoparticles}

The characteristic spectra of PS appeared at 698.00, 756.46, 2924.46, 3000.00, 3026.08, 3060.30, $3082.61 \mathrm{~cm}^{-1},{ }^{1}$ and that of $\mathrm{PB}$ appeared at: $\mathrm{C}=\mathrm{O}$ at $1728.21 \mathrm{~cm}^{-1}$; $\mathrm{C}-\mathrm{O}$ at $1272.64,1241.59$, and $1154.33 \mathrm{~cm}^{-1}$; and $-\left(\mathrm{CH}_{2}\right)_{3} \mathrm{CH}_{3}$ at $1067.94,965.46$, and $845.09 \mathrm{~cm}^{-1} .{ }^{2}$ As shown in Figure 4, the Fourier-transform infrared (FTIR) spectra of core-shell nanoparticle consisted both of the characteristic spectra of PS and PB, which confirms the existence of PS and PB in core-shell nanoparticle.

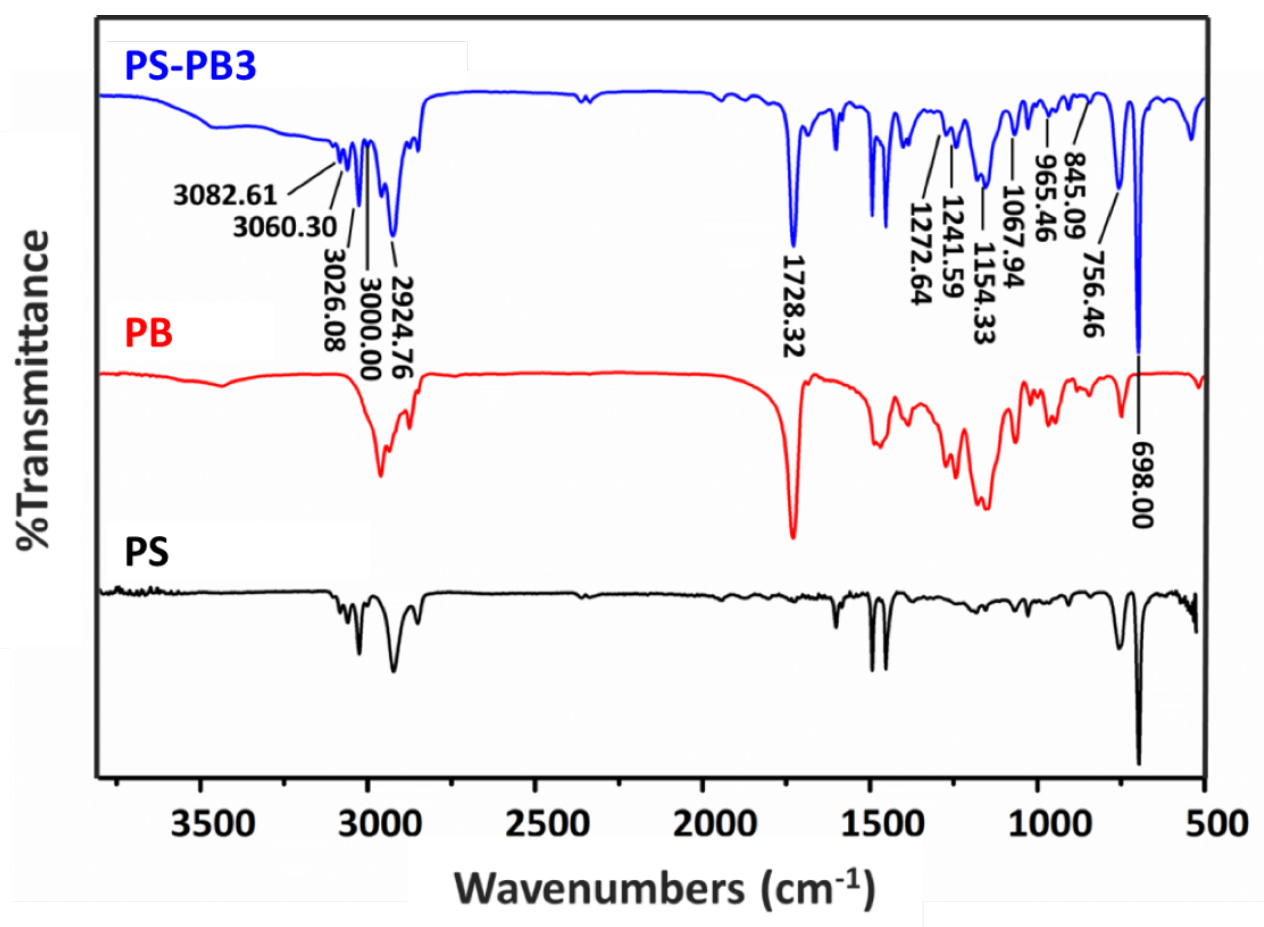

Figure S4. FTIR spectra of polystyrene seed nanoparticles, pure poly $n$-butyl methacrylate and synthesized polystyrene-core-poly( $n$-butyl methacrylate)-shell nanoparticles. 


\section{XPS of Nanoparticle Films}

The carbon/oxygen atomic ratio of PS and PS-PB nanoparticles are summarized in Table 1. The carbon/oxygen ratio of seed nanoparticle was determined as $100 \% / 0$, which agrees with the composition of polystyrene. The oxygen atomic composition of pure poly(n-butyl methacrylate) is $20 \%$. The measured values in Table 1 are slightly less.

Table S1. Atomic composition of PS and PS-PB3 nanoparticles determined by XPS.

\begin{tabular}{cccc}
\hline $\begin{array}{c}\text { Nanoparticle } \\
\text { designation }\end{array}$ & $\begin{array}{c}\text { Recorded electron } \\
\text { takeoff angle }\end{array}$ & $\begin{array}{c}\text { Carbon } \\
\text { Atomic\% }\end{array}$ & $\begin{array}{c}\text { Oxygen } \\
\text { Atomic\% }\end{array}$ \\
PS & $10^{\circ}$ & 100 & 0 \\
PS-PB3 & $10^{\circ}$ & 84.3 & 15.7 \\
& $90^{\circ}$ & 85.4 & 14.6 \\
\hline
\end{tabular}



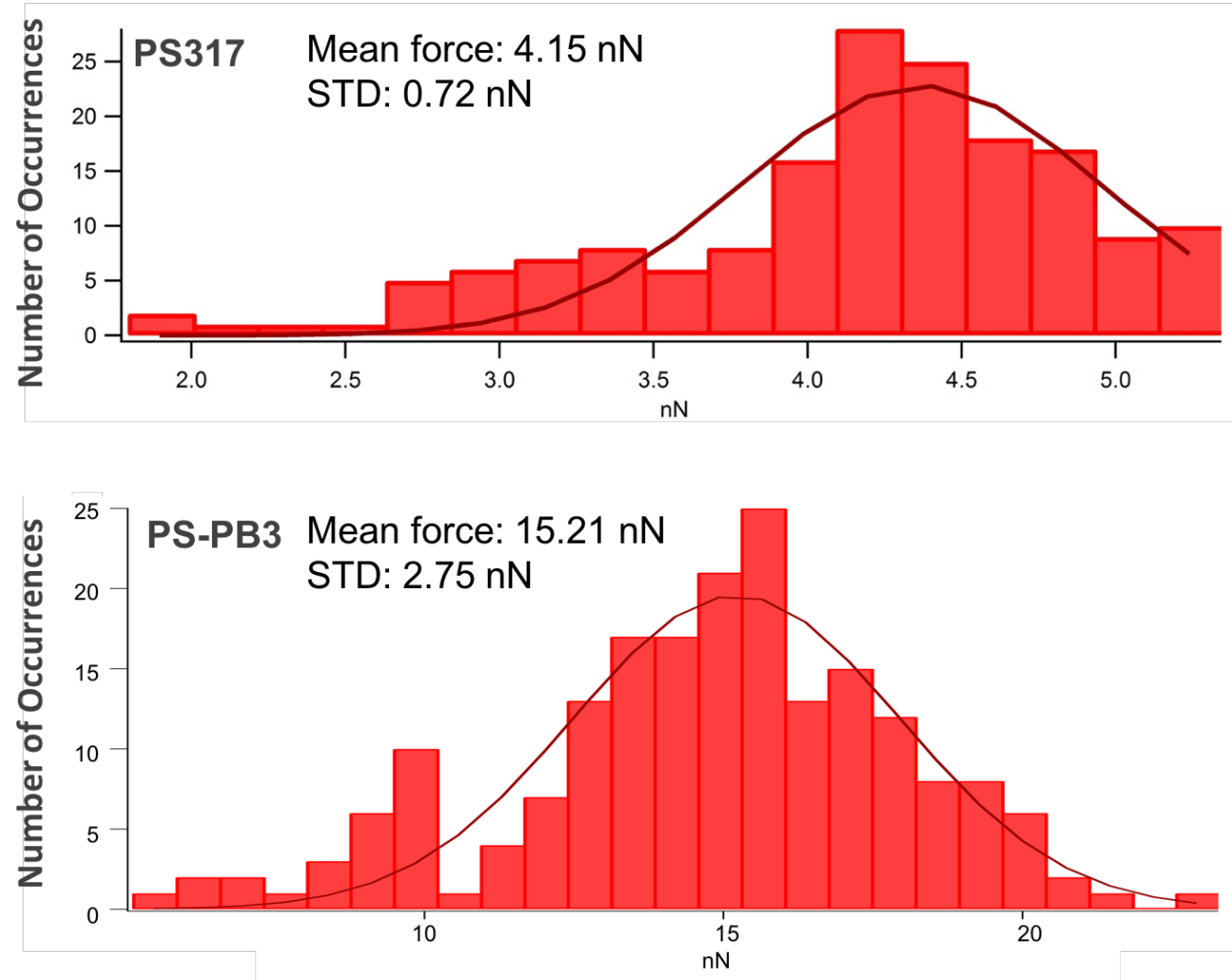

Figure S5. Distributions of the pull-off force based on 155 measurements for PS317 and 196 measurements for PS-PB3. Force was expressed as nano newtons, $\mathrm{nN}=10^{-9} \mathrm{~N}$. 
PS317 Pull-off Force Map

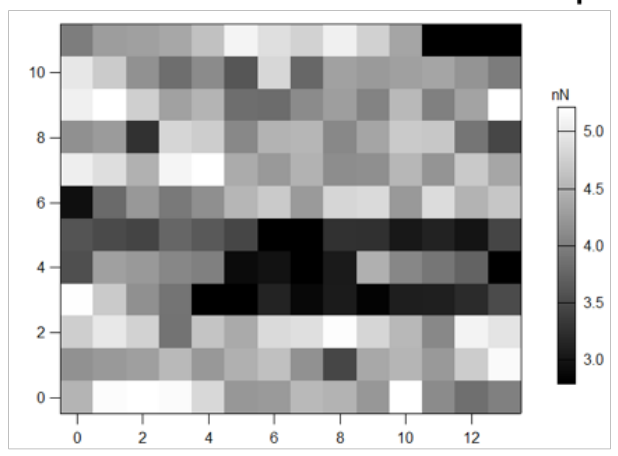

PS-PB3 Pull-off Force Map

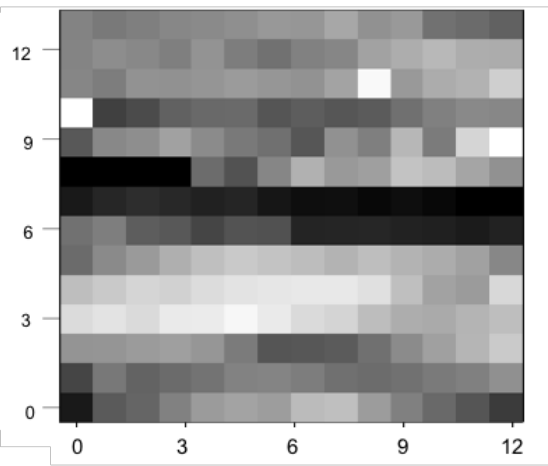

PS317 Adhesion Map

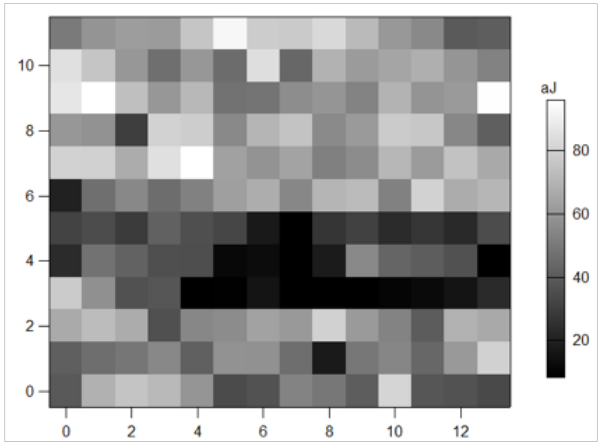

PS-PB3 Adhesion Map

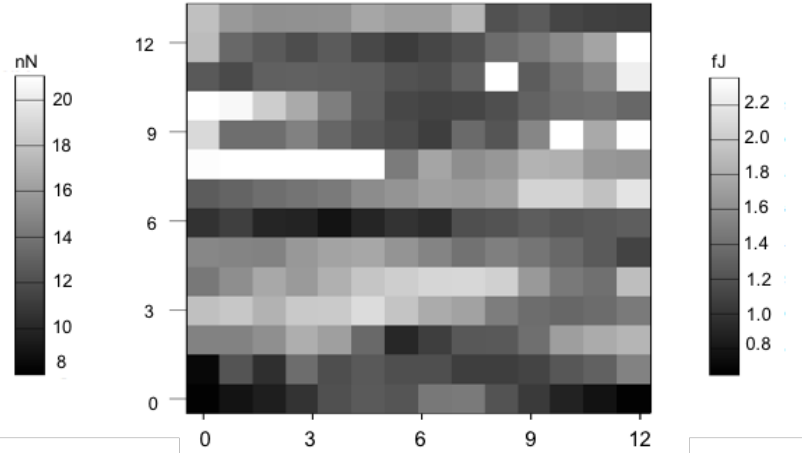

Figure S6. Sequential maps represent the distribution of pull-off force and adhesion work measurements in sequence form start to finish. Square at the top left origin $(0,0)$ represents the first measurement and the square diagonal to the origin at the bottom right represents the last measurement for that set. Force was expressed as nanonewton, $\mathrm{nN}=10^{-9} \mathrm{~N}$. Work was expressed as attojoules, a $=10^{-18} \mathrm{~J}$, and femtojoules, $\mathrm{fJ}=10^{-15} \mathrm{~J}$. 


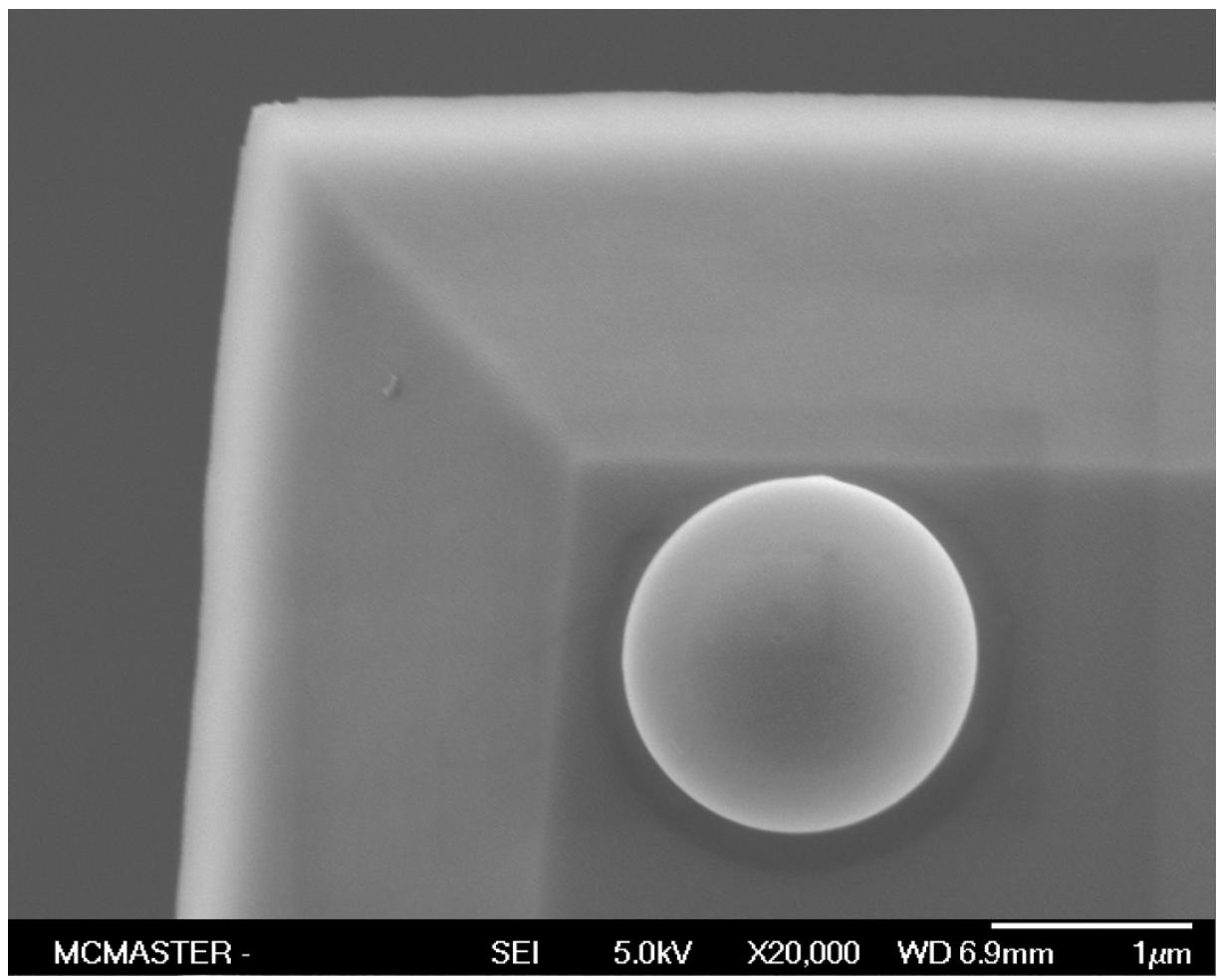

Figure S7. SEM image of AFM colloidal probe after performing over 100 colloidal probe AFM adhesion measurements against a PS-PB3 coated surface. 


\section{References}

(1) Liang, C. Y.; Krimm, S., Infrared Spectra of High Polymers. Vi. Polystyrene. J. of Polym. Sci. 1958, 27, 241-254.

(2) Peng, H.; Cheng, S.; Fan, Z., Synthesis and Characterization of Poly(N-Butyl Methacrylate)-B-Polystyrene Diblock Copolymers by Atom Transfer Radical Emulsion Polymerization. J. Appl. Polym. Sci. 2005, 98, 2123-2129. 